www.jmscr.igmpublication.org

Impact Factor 5.84

Index Copernicus Value: 71.58

ISSN (e)-2347-176x ISSN (p) 2455-0450

crossref DOI:_https://dx.doi.org/10.18535/jmscr/v5i11.102

Journal Of Medical Science And Clinical Research

\title{
Cardiac Manifestation involvement in Dengue Infection
}

\author{
Authors \\ Dr Rajiv Girdhar ${ }^{1}$, Dr Yogesh Kothari ${ }^{2}$, Dr Ram Anil Raj ${ }^{3}$, Dr Pandu Rahul ${ }^{4}$, \\ Dr Kumar Kenchappa ${ }^{5}$, Dr Narayan Raju ${ }^{6}$, Dr Prasanth Rai ${ }^{7}$, Dr Chaithra Kodmad \\ ${ }^{1}$ P.G in DM Cardiology, ${ }^{2}$ HOD \& Professor in Cardiology, ${ }^{3,5,6,7}$ Assistant Professor in Cardiology \\ ${ }^{4}$ P.G in General Medicine, ${ }^{8}$ Internship in Cardiology \\ Department of Cardiology, Rajarajeshwari Medical College \& Kengeri, Bengaluru
}

\begin{abstract}
Background and Objectives: Dengue is endemic in the tropics, and complications involving organ systems are seen with varying incidence.

The present study was conducted to find out the proportion of dengue fever cases with cardiac involvement. Materials and Methods: This is a descriptive study. 211 successive dengue fever cases were selected for the study. Appropriate investigations were done.

Results: It was found that a significant number of patients of dengue developed asymptomatic involvement of heart as evidenced by electrocardiography changes, raised cardiac enzymes.

Conclusion: Myocardial involvement in most of the cases was found to be subclinical on 2-D echo.

Keywords: Dengue, Myocardial Involvement.
\end{abstract}

\section{Background and Objectives \\ Introduction}

Dengue is one of the most important mosquitoborne illnesses worldwide ${ }^{[1]}$. It is a caused by a flavivirus with four distinct serotypes (DENV1, DENV2, DENV3, and DENV4). Current estimates project that 390 million infections occur annually, in over 100 countries, of which 96 million result in clinical disease with a case fatality rate of around $1 \%{ }^{[2]}$. Infection with one of the serotypes is thought to result in lifelong serotype-specific immunity. Serious disease is thought to occur mainly, though not exclusively, as a result of a second infection by a different serotype $^{[3]}$. The mechanisms that result in the development of the severe, life-threatening dengue shock syndrome remain an enigma. The primary pathophysiological phenomenon of the disease that occurs is acute vascular leakage, which lasts for 24-48 hours after its onset.

Despite being traditionally considered a disease of children, dengue is now known to affect individuals of any age, and results in significant economic impact. Dengue infection is difficult to control; no specific treatment or vaccine is available, and vector control is fraught with difficulties. There is no specific treatment for dengue ${ }^{[4]}$.

The natural history of dengue infection usually follows a clear pattern. The majority of infections are asymptomatic and subclinical. Symptomatic disease follows an incubation period of four to seven days, and begins as an acute febrile illness with high temperature, malaise, retro-orbital 
headache, myalgia, backache, nausea, loss of appetite, and vomiting ${ }^{[5]}$. For management purposes, clinical illness is divided into three phases: the febrile phase, the critical phase, and the recovery phase. Around the third to seventh day of illness, the critical phase, which is associated with a dropping platelet count, recovery of leukopenia, and defervescence, may begin. The critical phase is defined by the occurrence of features of plasma leakage: rising hematocrit, clinical or radiological evidence of third-space fluid leakage, and, in some cases, hypotension.

A proportion of patients develop severe clinical shock, of which a minority proceed to develop relentless severe intractable shock, coagulopathy with bleeding, and multi-organ failure, which can culminate in death ${ }^{[6]}$. As the incidence of dengue increases, reports of atypical manifestations are also on the rise, although these may be underreported because of lack of awareness and under-diagnosis of dengue ${ }^{[7]}$. The incidence of various complications, in both serologically diagnosed patients and those with merely a clinical diagnosis without supporting serology, is quite similar ${ }^{[8]}$. A variety of atypical manifestations of dengue have been described ${ }^{[7]}$. In one study of 913 schoolchildren with dengue, a wide variety of complications were observed: hepatitis (27\%), neurological alterations (25\%), renal impairment (7\%), cardiac involvement (8\%), pulmonary changes $(9 \%)$, acalculous cholecystitis (9\%), hemophagocytic syndrome $(2.5 \%)$, pancreatitis $(1 \%)$, and acute abdominal pain $(11 \%)^{[9]}$.

Cardiac involvement is not uncommon and is encountered in centers handling large numbers of dengue cases. Clinical manifestations of cardiac involvement can vary widely, from silent disease to severe myocarditis resulting in death. Rhythm abnormalities, hypotension, arrhythmias, myocarditis, myocardial depression with symptoms of heart failure and shock, and pericarditis have been reported. Involvement of multiple organs as well as the presence of metabolic derangement can further confuse the picture ${ }^{[10,11]}$. Still, the significance of cardiac involvement in dengue infection is not fully understood. Myocarditis, pericarditis, and cardiomyopathy after dengue have been reported in the literature from the 1970s ${ }^{[12-15]}$. During outbreaks, incidence of myocarditis as high as $13 \%$ has been reported; electrocardiographic changes have been noted in up to $62.5 \%$ of patients ${ }^{[16-17]}$.

The purpose of this study was to assess whether there is any form of cardiac involvement (Clinical or subclinical) in dengue and DHF, because most of our dengue patients had raised cardiac markers.

\section{Aims \& Objectives}

To find out the proportion of Dengue Fever cases with cardiac involvement.

\section{Materials \& Methods}

This study was conducted in the Rajarajeshwari Medical College \& Hospital, Mysore road, Bangaluru. It was a hospital based observational descriptive study and was carried out from April 2017 to September 2017. 211 eligible dengue fever cases fulfilling inclusion criteria were included basis after beginning of the study.

\section{Inclusion Criteria}

- Both primary dengue (NS-1 antigen or IgM or both positive) and secondary (NS-1 antigen or IgM and $\mathrm{IgG}$ antibody positive) dengue cases were included.

\section{Exclusion Criteria}

- All patients with fever who are Dengue IgM/NS1 Ag negative.

- Patients who had any known cardiac disease, chronic kidney disease, diabetes mellitus, hypertension were excluded.

The following parameters were considered and/or measured in all patients: Age, gender, blood pressure, routine blood inv., NS-1 antigen, IgM and IgG antibody, CK-MB, ECG, Trop-T, 2-D echo. Inferences were drawn with use of appropriate test of significance. The categorical data were presented as numbers (percent) and 


\section{JMSCR Vol||05||Issue||11||Page 30413-30420||November}

were compared among groups using Chi square test. Groups were compared for demographic data, were presented as mean and standard deviation and were compared using by students t-test. Probability $P$ value $<0.05$ was considered statistically significant.

\section{Results}

Table 1 Age Wise Distribution of Cases

\begin{tabular}{|l|c|c|}
\hline Age $($ Yrs $)$ & No. Of Cases & Percentage \% \\
\hline$<20$ & 43 & 20.37 \\
\hline $21-29$ & 71 & 33.64 \\
\hline $30-39$ & 49 & 23.22 \\
\hline $40-49$ & 18 & 8.53 \\
\hline $50-59$ & 18 & 8.53 \\
\hline$>59$ & 12 & 5.68 \\
\hline
\end{tabular}

Table 2 Gender Wise Distribution of Cases

\begin{tabular}{|l|c|c|}
\hline Gender & No. of Cases & Percentage \% \\
\hline Male & 110 & 52.13 \\
\hline Female & 101 & 47.87 \\
\hline
\end{tabular}

Table 3 Geographical Distribution of Cases

\begin{tabular}{|l|c|c|}
\hline Address & Cases & Percentage\% \\
\hline Ramnagar & 97 & 46 \\
\hline Channpatna & 54 & 26 \\
\hline Bidadi & 30 & 14 \\
\hline Kumbalgowdu & 16 & 8 \\
\hline Kambipur & 09 & 4 \\
\hline Kangeri & 05 & 2 \\
\hline
\end{tabular}

Table 4 ECG changes

\begin{tabular}{|l|c|c|}
\hline ECG changes & $\begin{array}{c}\text { No.of } \\
\text { Patients }\end{array}$ & Percentage \\
\hline With in normal limit & 154 & 72.98 \\
\hline Involved & 57 & 27.01 \\
\hline Generalized T wave inversion & 06 & 10.52 \\
\hline Sinus bradycardia & 18 & 31.57 \\
\hline Sinus tachycardia & 14 & 24.56 \\
\hline ST depression in V1-V6 & 6 & 10.52 \\
\hline ST depression in V1-V4 & 6 & 10.52 \\
\hline T wave inversion in V2-V5 & 4 & 7.01 \\
\hline T wave inversion in V2-V5 & 8 & 14.03 \\
\hline Generalised ST elevation & 1 & 1.75 \\
\hline Low voltage & 7 & 12.28 \\
\hline ST-T changes in V2-V5 & 4 & 7.01 \\
\hline ST-T changes in V3-V6 & 4 & 7.01 \\
\hline T wave inversion in lead 2,3 & 6 & 10.52 \\
\hline
\end{tabular}

Table 5 Dengue Cases According to CKMB with Cardiac Involvement

\begin{tabular}{|l|c|c|c|c|}
\hline $\begin{array}{l}\text { CK-MB } \\
\text { (U/L) }\end{array}$ & $\begin{array}{c}\text { No. of } \\
\text { Patients }\end{array}$ & Mean & $\begin{array}{c}\text { Std. } \\
\text { Deviation }\end{array}$ & P value LS \\
\hline Normal & 132 & 22.05 & 0.32 & $<0.0001 \mathrm{~S}$ \\
\hline Elevated & 79 & 94.62 & 5.64 & $<0.0001 \mathrm{~S}$ \\
\hline
\end{tabular}

Table 6 Distribution of Dengue Cases According to Abnormal Troponin $\mathrm{T}$ test with Cardiac Involvement

\begin{tabular}{|l|c|c|}
\hline Troponin T test & No of cases & Percentage \\
\hline Positive & 12 & 5.68 \\
\hline Negative & 199 & 94.32 \\
\hline Total & 211 & 100 \\
\hline
\end{tabular}

Table 7 Echo Finding with Cardiac Involvement

\begin{tabular}{|l|c|c|}
\hline Echo Finding & No. of Patients & Percentages \\
\hline $\begin{array}{l}\text { Global hypokinesia, LVEF- } \\
50 \%\end{array}$ & 2 & 3.50 \\
\hline Grade 1 diastolic dysfunction & 2 & 3.50 \\
\hline $\begin{array}{l}\text { LV systolic dysfunction, EF- } \\
49 \%\end{array}$ & 2 & 3.50 \\
\hline Mild MR, trivial TR & 2 & 3.50 \\
\hline Mild pericardial; effusion & 10 & 17.54 \\
\hline Severe LV dysfunction dilated, RV & 2 & 3.50 \\
\hline $\begin{array}{l}\text { RA,RV } \\
\text { hypokinesia }\end{array}$ & 2 & 3.50 \\
\hline Grade 1 LVDD, EF-53\% & 2 & 3.50 \\
\hline $\begin{array}{l}\text { Lt. Ventrivular hypokinesia } \\
\text { LVEF-45\% }\end{array}$ & 2 & 3.50 \\
\hline $\begin{array}{l}\text { Severe TR,Mild MR, LVEF- } \\
\text { 46\% }\end{array}$ & & 3.50 \\
\hline
\end{tabular}

Table 8 Assessment of Cardiac Involvement via Various Investigation Modalities

\begin{tabular}{|l|c|c|}
\hline Finding & No. of cases & Percentage \\
\hline Abnormal CK-MB(U/L) & 79 & 37.4 \\
\hline Abnormal ECG & 57 & 27.01 \\
\hline Abnormal Echo findings & 18 & 8.53 \\
\hline Abnormal Troponin T & 12 & 5.68 \\
\hline
\end{tabular}

Table 9 Distribution of Dengue Cases According to Cardiac Involvement

\begin{tabular}{|l|c|c|}
\hline Cardiac Involvement & No. of cases & Percentage \\
\hline Present & 57 & 27.01 \\
\hline Absent & 154 & 72.99 \\
\hline Total & 211 & 100 \\
\hline
\end{tabular}

In our study, maximum patients were within 20 to 39 years of age group. Out of 211 patients, most were male. (Table1,2)

Out of 211 dengue patients, abnormal ECG findings were in 57 patients, most common ECG 
finding was sinus bradycardia in 18 patients (31.57\%), next was sinus tachycardia in 14 patients $(24.56 \%)$ and $\mathrm{T}$-wave inversion in V1-V4 and V2-V5 was in 8 and 4 patients respectively. ST depression in V1-V4 and V1-V6 was in 6patients each, generalised $\mathrm{T}$ inversion in 6 patients and low voltage in 7 patients, ST-T changes in V2-V5 and V3-V6 both were in 4 patients each, generalised ST elevation in 1 patient and $\mathrm{T}$ wave inversion in lead 2, 3 were in 6 patients. (Table 4). Among these 57 patients, abnormal echo finding was present in 18 patients $(31.57 \%)$. The most common finding was mild pericardial effusion in 10 patients $(17.54 \%)$. (Table 7).

Among these 211 patients, the mean Value of CKMB (U/L) was significantly higher in the cases with cardiac involvement as compared to normal which was statistically significant $(\mathrm{P}<0.0001 \mathrm{~S})$ (Table 5).

Out of 211 patients, 12 patients (5.68\%) were troponin $\mathrm{T}$ positive and 199 (94.32\%) were troponin T Negative (Table 6).

Out of 211 patients, 79 patients (37.4\%) had elevated CK-MB and 57 patients $(27.01 \%)$ had abnormal ECG findings, and 18 patients $(8.53 \%)$ had abnormal 2-D echo and abnormal Troponin $\mathrm{T}$ seen in 12 patients $(5.68 \%)$. (Table 8 ).

Out of 211 patients, 57patients (27.01\%) had cardiac involvement and 154 patients (72.99) did not have cardiac involvement. (Table 9).

\section{Discussion}

Dengue fever is known to affect several systems in the human body. As in any viral myocarditis, only a portion of the patients $(8.65 \%)$ had 2-D echocardiographic evidence of myocarditis. Myocardial involvement may be a result of the direct effect of the dengue virus in susceptible individuals, or due to the effects of cytokine mediators and/or cellular components of the immune response.

Clinical features, electrocardiographic abnormalities, abnormal cardiac biomarkers, and echocardiographic findings have been evaluated in various studies as possible markers of cardiac involvement in dengue.

In the present study, a total of 211 patients of Dengue fever were analyzed. The most common age group affected in our study was 20-39 years $(53 \%)$.

Table 10

\begin{tabular}{|l|c|c|c|c|}
\hline SI.No. & Author & Year & Place & Age (yrs) \\
\hline 1. & Baruah J & 2002 & MANIPAL & $5-20$ \\
\hline 2. & $\begin{array}{c}\text { Dash PK et } \\
\text { al }\end{array}$ & 2003 & Gwalior & $<15$ \\
\hline 3. & Neeraja M & 2004 & Hyderabad & $20-39$ \\
\hline 4. & $\begin{array}{c}\text { Present } \\
\text { study }\end{array}$ & 2017 & $\begin{array}{c}\text { RRMCH, } \\
\text { Mysore road }\end{array}$ & $20-39$ \\
\hline
\end{tabular}

This is comparable to the study done by Neeraja et al in 2004, in Hyderabad. ${ }^{[18]}$

The mean age in the present study is 30.45 years. This is comparable to the study done by Gupta et al (30.15 years) in 2008, in New Delhi. ${ }^{[19]}$ In our study, the incidence among males and females is almost equal. This is comparable to the study done by Dash P K et al in 2003, in Gwalior. ${ }^{[20]}$

Table 11

\begin{tabular}{|l|c|c|c|c|}
\hline SI.No. & Author & Year & Place & $\begin{array}{c}\text { M:F } \\
\text { Ratio }\end{array}$ \\
\hline 1. & $\begin{array}{c}\text { Dash PK et } \\
\text { al }\end{array}$ & 2003 & Gwalior & $1.28: 1$ \\
\hline 2. & Neeraja M & 2004 & Hyderabad & $2: 1$ \\
\hline 3. & Gupta et al & 2008 & New Delhi & $1.8: 1$ \\
\hline 4. & $\begin{array}{c}\text { Present } \\
\text { study }\end{array}$ & 2017 & $\begin{array}{c}\text { RRMCH, } \\
\text { Mysore road }\end{array}$ & $1.08: 1$ \\
\hline
\end{tabular}

Amongst the cases in our study, $46 \%$ cases were from Ramnagara, $26 \%$ cases were from Channpatna, $14 \%$ cases from Bidadi, $8 \%$ cases from Kumbalgowdu, 4\% from Kambipura \& 2\% case from Kangeri

In present study, above findings also observed for cardiac involvement in dengue. The presence of electrocardiogram (ECG) abnormalities has been used by some authors to denote cardiac involvement in dengue. ${ }^{[21]} \mathrm{A}$ diverse range of ECG abnormalities have been reported with dengue, including rate and rhythm abnormalities, heart block, wave form abnormalities, and voltage abnormalities. ${ }^{[22-33]}$

Reported rhythm abnormalities include relative bradycardia, ${ }^{[23]}$ sinoatrial block, ${ }^{[24]}$ disorders of 
atrioventricular conduction (Junctional rhythm), ${ }^{[24,25]}$ second-degree ${ }^{[26]}$ and complete heart block, [22,27] and monomorphic premature ventricular contractions on a background of heart block, ${ }^{[26]}$ atrial flutter, ${ }^{[28]}$ transient $^{[22,29]}$ and persistent ${ }^{[30]}$ atrial fibrillation, self-limiting tachy-brady arrhythmia, ${ }^{[34]}$ sinoatrial block, and uniform ventricular ectopics progressing to ventricular bigeminy. ${ }^{[31]}$ Electrocardiographic features mimicking acute myocardial infarction have also been reported. ${ }^{[33]}$ ECG abnormalities may go undetected or asymptomatic.

Cardiac arrhythmias are other clinical manifestations of myocarditis. Various arrhythmias have been described during dengue virus infection such as atrial fibrillation, ventricular tachycardia and even atrioventricular blocks. These arrhythmias are associated to syncope and even sudden death. [35-37]

In present study, out of 211 dengue patients, abnormal ECG findings were in 57 patients (27.01\%), most common ECG finding was sinus bradycardia in 18 patients $(31.57 \%)$, next was sinus tachycardia in 14 patients $(24.56 \%)$, and $\mathrm{T}$ wave inversion in V1-V4 and V2-V5 was in 4 and 2 patients respectively. ST depression in V1-V4 and V1-V6 was in 6 patients each, generalised T inversion in 6 patients and low voltage in 7 patient, ST-T changes in V2-V5 and V3-V6 both were in 4 patients each, generalised ST elevation in 1 patient and $\mathrm{T}$ wave inversion in lead 2, 3 were in 6 patient. Sinus bradycardia (Nimmannitiya S. et al) ${ }^{[36]}$ was the most conspicuous ECG finding with dengue fever but heart rate not useful.

Clinical manifestations suggesting cardiac involvement in dengue are diverse and include chest pain, palpitations, pleurisy, irregularities of pulse, bradycardia, hypotension, pulmonary oedema, and features of shock. ${ }^{[38,34]}$

It is known that tachycardia and hypotension is more frequently seen in DSS (Ranjit S et al). ${ }^{[37]}$ Also in our study 5 patients had hypotension and 11 patients had tachycardia, that is more common in DSS/DHF. Thus, although this study provides some evidence that patients with ECG changes were more likely to develop hypotension and tachycardia or bradycardia, it does not provide convincing evidence that cardiac involvement was present.

In present study out of 211 dengue patients, we observed elevated CK-MB in 79 (37.4\%), troponin $\mathrm{T}$ test was positive in $12(5.68 \%)$ patients. Myocardial involvement was subclinical as 2-D echo was normal in 17 patients $(60.71 \%)$. Possible cause of raised cardiac enzymes in these patients is subclinical myocarditis.

Cardiac biomarkers may indicate the presence of cardiac involvement in dengue. A prospective study in Sri Lanka (Wichmann, et al) ${ }^{[39]}$ evaluated several cardiac biomarkers (myoglobin, CK-MB, Troponin T, NT- pro-brain natriuretic peptide, heart-type fatty acid-binding protein), in patients. with dengue $25 \%$ of patients had abnormal results in one or more biomarkers. However, the correlation between biomarkers and cardiac function has not been clearly demonstrated.

A study (Gupta V K et al) ${ }^{[19]}$ was conducted in New Delhi for estimating cardiac enzymes in 28 patients of Dengue fever. Estimation of cardiac enzymes was done in all patients. Significant level of CPK-MB was raised in 22 patients $(78.55 \%)$. Serum troponin $\mathrm{T}$ (Rapid card test) was weakly positive in 12 patients (42.8\%). Myocardial involvement was subclinical as 2-D echo was normal in 23 patients (82\%). Possible cause of raised cardiac enzymes in these patients was subclinical myocarditis.

Out of 211 dengue patients, the cardiac involvement was in 57 patients. Among these 57 patients, abnormal echo finding was present in 18 patients $(31.55 \%)$. The most common finding was mild pericardial effusion in 10 patients $(17.54 \%)$.

Echocardiographic evidence of myocardial involvement in dengue has been clearly demonstrated. $^{[40,41,42]}$

In a study of 91 children with dengue, LVEF $<50 \%$ was observed in $6.7 \%, 13.8 \%$, and $36 \%$ of patients with DF, DHF, and DSS, respectively. 
Similarly, in our study LVEF $<50 \%$ was observed in $3.50 \%, 3.50 \%$ and $7 \%$ of patients with DF, DHF, and DSS, respectively.

In another study of 54 children under 12 years of age, LVEF was reduced $(<50 \%)$ in nine cases, and two had LVEF below 35\% (Kabra SK, et al) [43]

Satarasinghe et $\mathrm{al}^{[40]}$ demonstrated echocardiographic evidence of myocarditis in $24 \%$ of patients with dengue, cardiac dilatation, the most commonly demonstrated echocardiographic evidence of myocarditis, more commonly affected - the right ventricle (57\%), and associated with tricuspid regurgitation. Left ventricular dilatation was seen in $21 \%$ of patients, and biventricular dilatation in $16 \%$.

In our study, we also observed that right ventricle dilation (7\%) was more common and it was associated with tricuspid regurgitation. Left ventricular dilatation was seen in $3.50 \%$ of patients.

Sengupta et al ${ }^{[44]}$ also demonstrated similar evidence of myocarditis in patients with dengue, and suggest that two-dimensional (2-D) speckle tracking echocardiography may be a more sensitive tool for the detection of early and subtle myocarditis.

Cardiac magnetic resonance (CMR) imaging, where available, may be of value in confirming the diagnosis of myocarditis, with a positive predictive value of $95 \%$ if at least two of the three diagnostic criteria are present.

\section{Conclusion}

Dengue is a serious problem in the tropics. Cardiac involvement is worrisome for both the clinician and patient. A significant number of patients of dengue developed asymptomatic involvement of heart as evidenced by electrocardiography changes, raised cardiac enzymes (CPK-MB, S. trop. T, LDH and SGOT). Myocardial involvement was subclinical as 2-D echo was normal in 34 patients (60\%). Possible cause of raised cardiac enzymes in these patients is subclinical myocarditis. Asymptomatic myocarditis appears to be common in dengue, and spontaneous uneventful recovery is the norm.

Sinus bradycardia was the most conspicuous ECG finding; however, an echocardiogram is the gold standard for diagnosing myocardial involvement. Further studies are needed to evaluate the hemodynamic impact of myocardial involvement in patients with severe dengue. Most forms of treatment currently are purely supportive, but with better understanding of the pathophysiology of dengue, targeted treatment may become possible.

\section{References}

1. Raheel U, Faheem M, Riaz MN, Kanwal N, Javed F, Zaidi N, Qadri I (2011) Dengue fever in the Indian Subcontinent: an overview. J Infect Dev Ctries 5: 239247. doi:10.3855/jidc. 1017.

2. Bhatt S, Gething PW, Brady OJ, Messina JP, Farlow AW, Moyes CL, Drake JM, Brownstein JS, Hoen AG, Sankoh O, Myers MF, George DB, Jaenisch T, Wint GR, Simmons CP, Scott TW, Farrar JJ, Hay SI (2013) The global distribution and burden of dengue. Nature 496: 504-507.

3. Halstead SB (1988) Pathogenesis of dengue: challenges to molecular biology. Science 239: 476-481.

4. Rajapakse S, Rodrigo C, Rajapakse A (2012) Treatment of dengue fever. Infect Drug Resist 5: 103-112.

5. World Health Organization (2009) Dengue: Guidelines for Diagnosis, Treatment, Prevention \& Control. Available: http://whqlibdoc.who.int/publications/200 9/9789241547871_eng.pdf. Accessed 20 December 2014.

6. Sam SS, Omar SF, Teoh BT, Abd-Jamil J, AbuBakar S (2013) Review of Dengue hemorrhagic fever fatal cases seen among adults: a retrospective study. PLoS Negl Trop Dis 7: e2194.

7. Gulati S, Maheshwari A (2007) Atypical manifestations of dengue. Trop Med Int Health 12: 1087-1095. 
8. Kularatne SA, Gawarammana IB, Kumarasiri PR (2005) Epidemiology, clinical features, laboratory investigations and early diagnosis of dengue fever in adults: a descriptive study in Sri Lanka. Southeast Asian J of Trop Med \& Pub Health 36: 686-692.

9. Mendez A, Gonzalez G (2006) Abnormal clinical manifestations of dengue hemorrhagic fever in children. Biomedica 26: 61-70.

10. Naresh G, Kulkarni AV, Sinha N, Jhamb N, Gulati S (2008) Dengue hemorrhagic fever complicated with encephalopathy and myocarditis: a case report. J Com Dis 40: 223-224.

11. Gupta N, Kulkarni AV, Sinha N, Jhamb R, Gulati S (2010) Dengue hemorrhagic fever complicated with encephalopathy and mycocarditis. J Com Dis 42: 297-299.

12. Obeyesekere I, Hermon Y (1972) Myocarditis and cardiomyopathy after arbovirus infections (dengue and chikungunya fever). Brit Heart J 34: 821-827.

13. Nagaratnam N, Siripala K, de Silva N (1973) Arbovirus (dengue type) as a cause of acute myocarditis and pericarditis. Brit Heart J 35: 204-206.

14. Obeyesekere I, Hermon Y (1973) Arbovirus heart disease: myocarditis and cardiomyopathy following dengue and chikungunya fever--a follow-up study. Am Heart J 85: 186-194.

15. Pongpanich B, Kumponpant S (1973) Studies of dengue hemorrhagic fever. V. Hemodynamic studies of clinical shock associated with dengue hemorrhagic fever. J Pediatrics 83: 1073-1077.

16. Kularatne SA, Pathirage MM, Kumarasiri PV, Gunasena S, Mahindawanse SI (2007) Cardiac complications of a dengue fever outbreak in Sri Lanka, 2005. Trans Royal Soc Trop Med \& Hyg 101: 804-808.

17. Salgado DM, Rodriguez JA, Garzon M, Cifuentes G, Ibarra M, Vega MR, Castro
D (2007) Clinical and epidemiological characterisation of dengue haemorrhagic fever in Neiva, Colombia, 2004. Rev Salud Pub 9: 53-63.

18. Neeraja M, Lakshmi V, Teja VD, Umabala $\mathrm{P}$ and Subbalakshmi MV. Serodiagnosis of dengue virus infection in patients presenting to a tertiary care hospital. Indian J Med Microbiol 2006; 24: 280-2.

19. Vishal Kumar Gupta, AK Gadpayle. Subclinical Cardiac Involvement in Dengue Hemorrhagic Fever. JIACM 2010; 11(2): 107-11.

20. Dash PK, Saxena P, Abhavankar A, Bhargava R and Jana AM. Emergence of dengue virus type 3 in Northern India. Southeast Asian J Trop Med Public Health 2005; 36: 370-7.

21. Kularatne SA, Pathirage MM, Kumarasiri $\mathrm{PV}$, et al. Cardiac complications of a dengue fever outbreak in Sri Lanka, 2005. Trans R Soc Trop Med Hyg 2007;101(8):804-8.

22. Saldarriaga C, Roncancio G, González N, et al. Manifestaciones cardiacas del dengue. Reporte de una serie de casos durante la epidemia colombiana de 2010. Rev Colomb Cardio 2013;20(6):366-9.

23. Lateef A, Fisher DA, Tambyah PA. Dengue and relative bradycardia. Emerg Inf Dis 2007;13(4):650-1.

24. Kaushik JS, Gupta P, Rajpal S, et al. Spontaneous resolution of sinoatrial exit block and atrioventricular dissociation in a child with dengue fever. Sing Med J 2010;51(9):e146-8.

25. Donegani E, Briceno J. Disorders of atrioventricular conduction in patients with hemorrhagic dengue. Minerva Cardioangiolog 1986;34(7-8):477-80.

26. Khongphatthallayothin A, Chotivitayatarakorn P, Somchit S, et al. Morbitz type I second degree AV block during recovery from dengue hemorrhagic fever. Southeast 
Asian J of Trop Med \& Pub Health 2000;31(4):642-5.

27. Kohli U, Sahu J, Lodha R, et al. Invasive nosocomial aspergillosis associated with heart failure and complete heart block following recovery from dengue shock syndrome. Ped Crit Care Med 2007;8(4):389-91.

28. Silva FT, da Silva GB, Benevides AN, et al. Atrial flutter complicating severe leptospirosis: a case report. Rev Soc Bras Med Trop 2013;46(2):246-8.

29. HortaVeloso H, Ferreira JA, de Paiva $\mathrm{BJM}$, et al. Acute atrial fibrillation during dengue hemorrhagic fever. Brazil J Inf Dis 2003;7(6):418-22.

30. Mahmod M, Darul ND, Mokhtar I, et al. Atrial fibrillation as a complication of dengue hemorrhagic fever: non-selflimiting manifestation. Int $\mathrm{J}$ Inf Dis 2009;13(5):e316-8.

31. Chuah SK. Transient ventricular arrhythmia as a cardiac manifestation in dengue haemorrhagic fever--a case report. Sing Med J 1987;28(6):569-72.

32. La-Orkhun V, Supachokchaiwattana P, Lertsapcharoen $\mathrm{P}$, et al. Spectrum of cardiac rhythm abnormalities and heart rate variability during the convalescent stage of dengue virus infection: a Holter study. An Trop Paed 2011;31(2):123-8.

33. Lee $\mathrm{CH}$, Teo $\mathrm{C}$, Low AF. Fulminant dengue myocarditis masquerading as acute myocardial infarction. Int $\mathbf{J}$ Cardiol 2009;136(3):e69-71.

34. 34. Lee IK, Lee WH, Liu JW, et al. Acute myocarditis in dengue hemorrhagic fever: a case report and review of cardiac complications in dengue-affected patients. Int J Inf Dis 2010;14(10):e919-22.

35. Punja M, Mark DG, McCoy JV, et al. Electrocardiographic manifestations of cardiac infectious-inflammatory disorders. Am J Emerg Med 2010;28(3):364-77.
36. Dengue NS. Dengue hemorrhagic fever. In: Manson's tropical diseases. 20th edn. London: WB Saunders 1996:712-29.

37. Ranjit S, Kissoon N, Gandhi D, et al. Early differentiation between dengue and septic shock by comparison of admission hemodynamic, clinical, and laboratory variables: a pilot study. Ped Emerg Care 2007;23(6):368-75.

38. Promphan W, Sopontammarak S, Pruekprasert P, et al. Dengue myocarditis. Southeast Asian J Trop Med Public Health 2004;35(3):611-3.

39. Wichmann D, Kularatne S, Ehrhardt S, et al. Cardiac involvement in dengue virus infections during the 2004/2005 dengue fever season in Sri Lanka. Southeast Asian J Trop Med Public Health 2009;40(4):72730.

40. Satarasinghe RL, Arultnithy K, Amerasena NL, et al. Asymptomatic myocardial involvement in acute dengue virus infection in a cohort of adult Sri Lankans admitted to a tertiary referral centre. Brit $\mathbf{J}$ Cardiol 2007;14:171-3.

41. Wali JP, Biswas A, Chandra S, et al. Cardiac involvement in dengue haemorrhagic fever. Int J Cardiol 1998;64(1):31-6.

42. Miranda CH, Mde BC, Matsuno AK, et al. Evaluation of cardiac involvement during dengue viral infection. Clin Inf Dis 2013;57(6):812-9

43. Ehrhardt S, Mockenhaupt FP, Anemana $\mathrm{SD}$, et al. High levels of circulating cardiac proteins indicate cardiac impairment in African children with severe plasmodium falciparum malaria. Microbes Infect 2005;7(11-12):1204-10.

44. Sengupta SP, Nugurwar A, Jaju R, et al. Left ventricular myocardial performance in patients with dengue hemorrhagic fever and thrombocytopenia as assessed by twodimensional speckle tracking echocardiography. Indian Heart J 2013;65(3):276-82. 